\title{
MICROSTRUCTURE INVESTIGATION AND SELECTED PROPERTIES OF NI-CR-RE COATINGS DEPOSITED BY MEANS OF PLASMA SPRAYING
}

\author{
${ }^{1}$ Konrad TOBOTA, ${ }^{1}$ Beata SKOWROŃSKA, ${ }^{2}$ Marcin CHMIELEWSKI, ${ }^{1}$ Rafał ŚWIERCZ, \\ ${ }^{1}$ Tadeusz SAŁACIŃSKI, ${ }^{1}$ Tomasz CHMIELEWSKI \\ ${ }^{1}$ Warsaw University of Technology, Faculty of Production Engineering, Warsaw, Poland, EU, \\ konrad.tobota.dokt@pw.edu.pl \\ ${ }^{2}$ Łukasiewicz Research Network, Centre of Electronic Materials Technology, Warsaw, Poland, EU, \\ marcin.chmielewski@imif.lukasiewicz.gov.pl
}

https://doi.org/10.37904/metal.2021.4192

\begin{abstract}
The article presents selected results of microstructural investigation of $\mathrm{Ni}$-Cr-Re coatings deposited by means of plasma thermal spray. The substrate made of $16 \mathrm{Mo} 3$ chromium molybdenum boiler steel was sprayed with a powder material of Oerlikon Amdry $453580 \% \mathrm{Ni}, 20 \% \mathrm{Cr}, 20 \div 45 \mu \mathrm{m}$, to which $1 \%$ of metallic rhenium was added. Rhenium are an alloying additive that improves the heat resistance of alloys, creep, and high temperature oxidation resistance. Alloys with the addition of rhenium are widely used in aviation and power industry. Metallographic microscopic examinations, microhardness tests and surface profilometry were carried out.
\end{abstract}

Keywords: Thermal spraying, protective coating, heat resistance, microstructure, Re addition, rhenium, coating

\section{INTRODUCTION}

The Plasma spraying process is essentially spraying molten or softened by heat (plasticized) materials onto a surface to form a coating. Materials in the form of a wire or powder are injected into a high temperature plasma flame, where it's heated and accelerated to very high speed of flux. Plasma spraying diagram is shown in (Figure 1). Metallic, ceramics and even composite powders are commonly used. The most common plasmaforming gas in the spraying process is argon or a mixture of argon and hydrogen. Coatings with a thickness of $0.05 \div 2 \mathrm{~mm}$ and a density of up to $98 \%$ are mostly obtained [1-3].

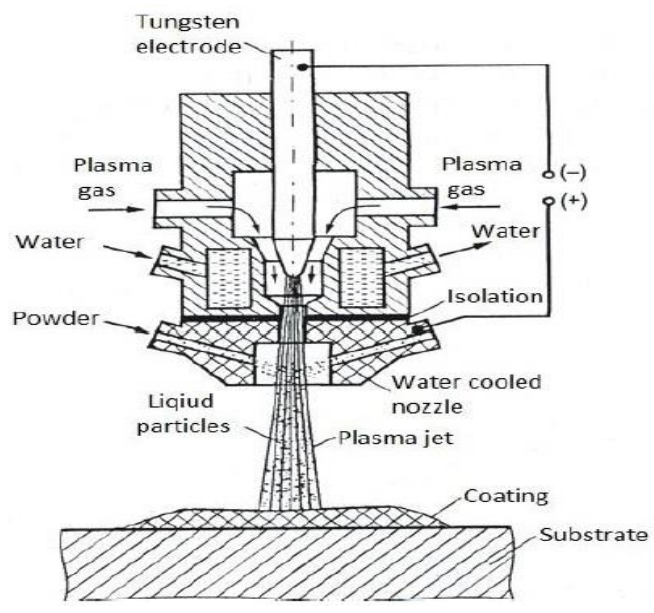

Figure 1 Diagram of plasma spraying process [1] 
For the proper adhesion of the coating, the surface of the substrate must be prepared properly, and the process parameters must be carefully selected. A well-prepared surface is considered as a dry, degreased surface, free from oxides and impurities, and above all, with an appropriate roughness. The surface profile should be irregular and heterogeneous and have a kind of "nests" in which particles of plasticized material can be deposited [2-4].

The aim of the work is to prepare and evaluate coatings in accordance with the developed technology of plasma spraying of nickel-chromium powder with the addition of Rhenium ( $\mathrm{Ni}-\mathrm{Cr}-\mathrm{Re}$ ) on the substrate made of $16 \mathrm{Mo} 3$ boiler steel and testing the obtained coatings.

Rhenium is a dark silvery refractory transition metal element with an atomic number of 75 and an atomic mass of 186.2 . It has a very high melting point $\left(3180^{\circ} \mathrm{C}\right)$. Young's modulus $(470 \mathrm{GPa})$. It is characterized by the fourth highest density $(21.02 \mathrm{~g} / \mathrm{cm} 3)$. At $2700 \div 2800^{\circ} \mathrm{C}$ and under high stress conditions, the tensile and creep strength of Rhenium at high temperature is much higher than that of tungsten (at temperatures up to $1250^{\circ} \mathrm{C}$ it exceeds twice). The addition of Rhenium to the $\mathrm{Ni}-\mathrm{Cr}$ powder is to increase the thermal resistance of the obtained coating and to improve the resistance to high-temperature oxidation [5].

\section{METHODS, MATERIALS AND DEVICES}

The main coating material powder was Amdry $4535 \mathrm{Ni}-\mathrm{Cr}$ (80\%-20\%) from Oerlikon company, Re powder from KGHM with $150 \mu \mathrm{m}$ granulation (purity 99.7\%). The morphology of the starting powders is shown in (Figure 2).
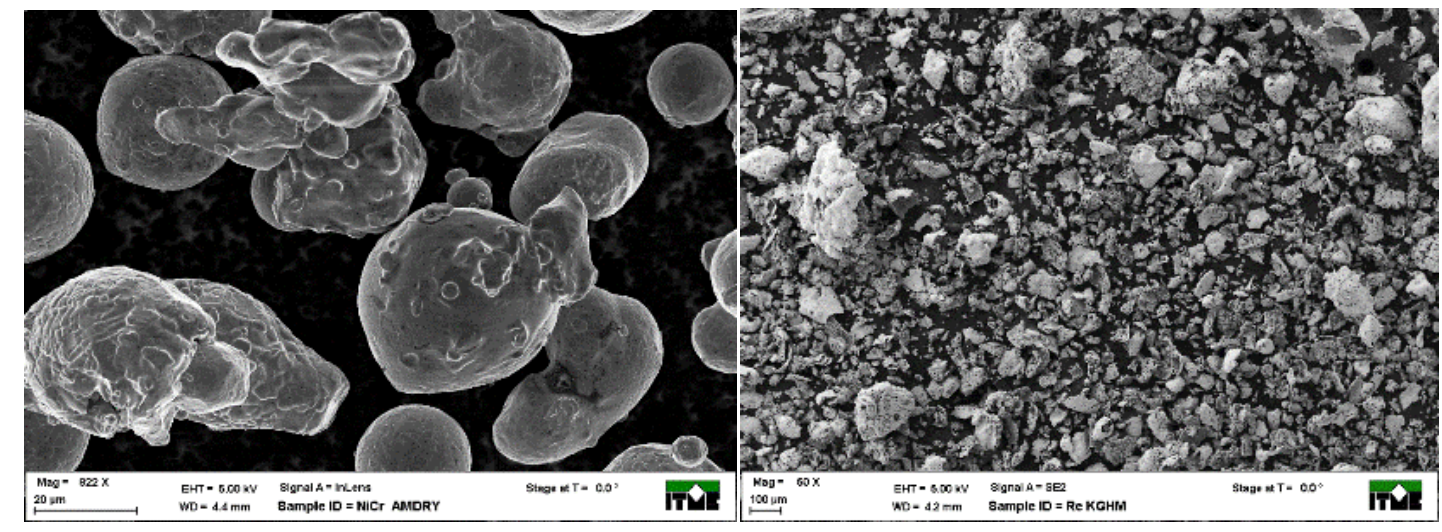

Figure 2 SEM images of: Ni-Cr powder (left), Re powder (right)

Due to the relatively large initial size of rhenium grains, it was subjected to a process of grinding by milling in a high-energy planetary mill with the following parameters: $200 \mathrm{rpm}$, BPR 5: 1, time $4 \mathrm{~h}$. After mixing, the powders were subjected to microscopic observation. In addition, surface distribution analysis of the elements (EDS) was performed. The morphology of the obtained powder mixtures is shown in (Figure 3).
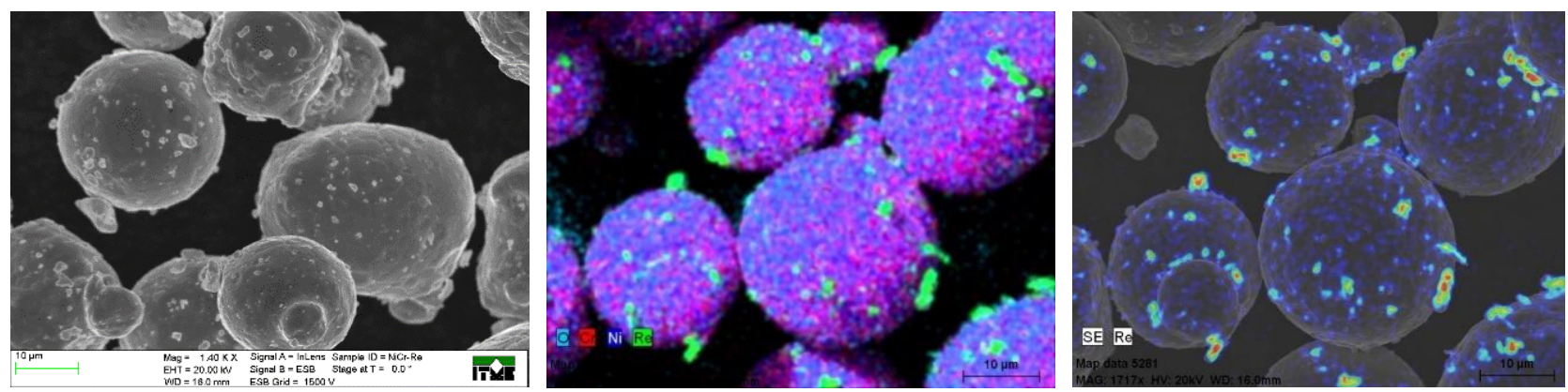

Figure 3 Morphology and surface distribution of the elements of the $\mathrm{NiCr}+1 \mathrm{vol} . \% \mathrm{Re}$; red-Cr, blue-Ni, green-Re 
SEM images and surface analysis of the elements showed that the Rhenium powder introduced into the mixture tends to hammer to the $\mathrm{Ni}-\mathrm{Cr}$ particles.

The coatings were made using the Multiprocess Spray System MP100. Prior to spraying, the powder was dried at $300^{\circ} \mathrm{C}$ for 50 hours and then sieved through a $50 \mu \mathrm{m}$ sieve. 10 steel plates are welded to the C-profile steel to avoid shifting during spraying, allowing a uniform coating and better heat dissipation. The substrate was grit blasted with F36 alumina. The roughness Ra after blasting averaged $6,5 \mu \mathrm{m}$. The channel was attached to the vertical truss of the rack (Figure 4 left). The plasma forming gas was a mixture of argon and helium. The additive material in the form of a powder was supplied with an argon stream.
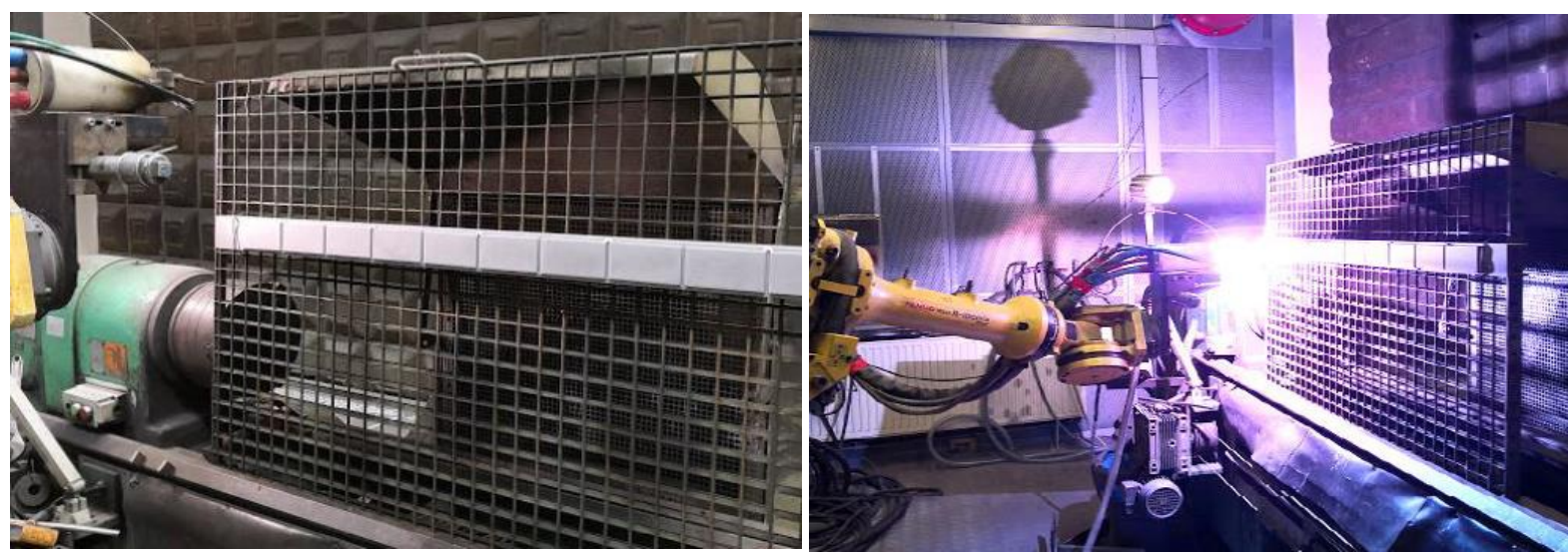

Figure 4 Method of fixing plasma spray samples on a common beam (left), Fanuc R-100iA robot while spraying (right)

The F4 plasma torch was mounted on the FANUC R-100iA robot arm (Figure 4 right), which allows unlimited, free generation of the plasma torch trajectory. Thanks to this, the process was carried out repeatedly, precisely maintaining a constant distance between the torch and the ground.

\section{RESULTS}

Coatings with a thickness of about $500 \mu \mathrm{m}$ were obtained. Before the invasive and destructive tests, optical roughness measurements were carried out on the Sensofar S Neox profilometer. The surface roughness of the coating was measured. The three-dimensional map of the coating surface distribution is shown in the (Figure 5).

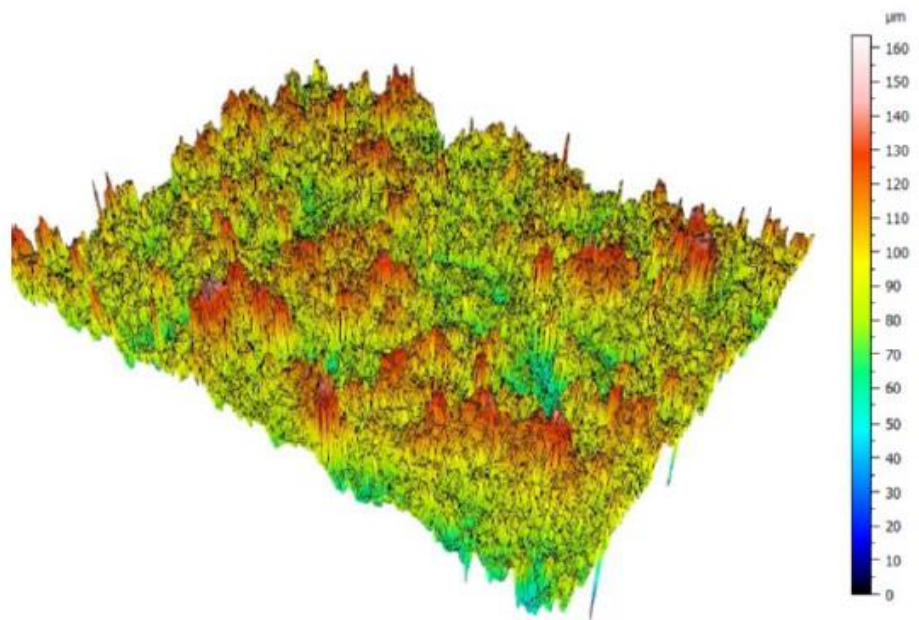

Figure 5 Three-dimensional map of coating surface deposited by the means of plasma spraying 
Figure 6 shows the microstructure of the substrate-coating system. The $16 \mathrm{Mo} 3$ steel substrate with a ferriticpearlitic structure is characterized by an even grain distribution.
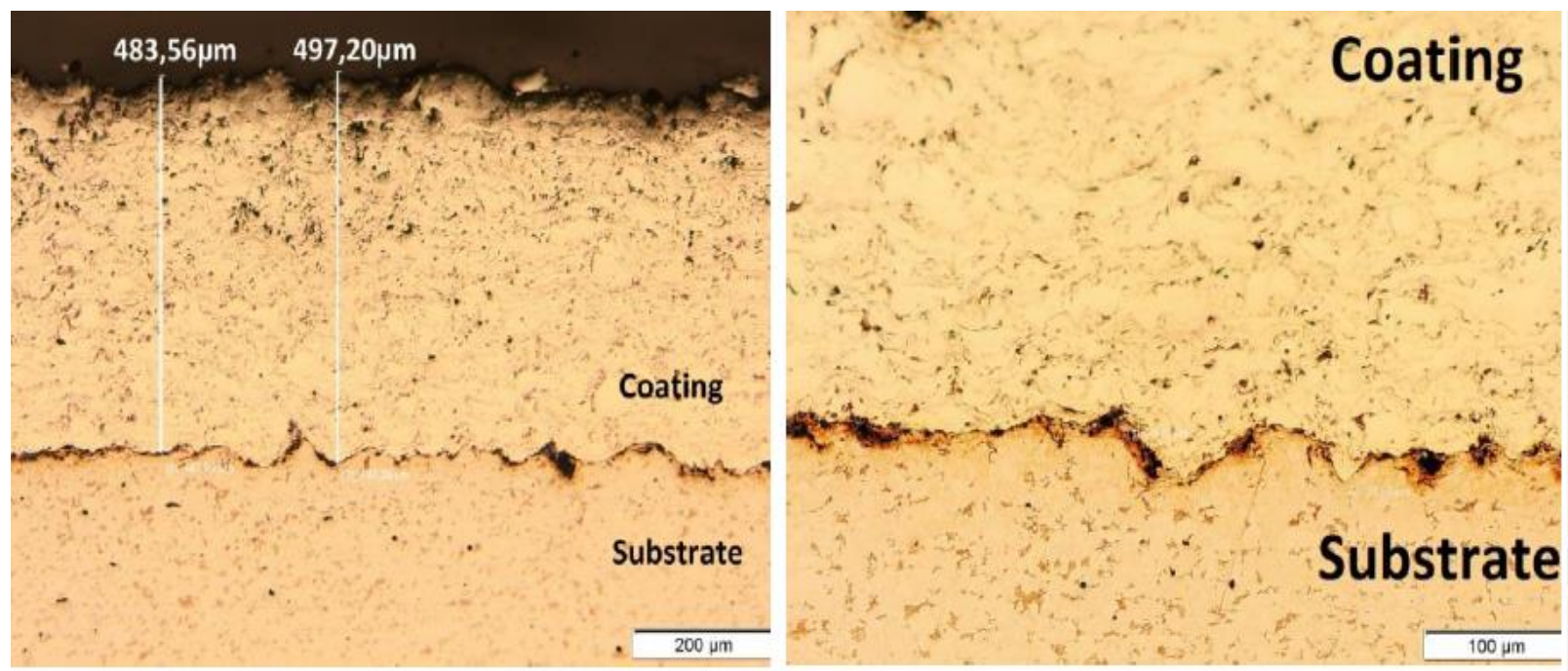

Figure 6 Microstructure of 16Mo3 steel substrate and Ni-Cr-Re coating

Figure 7 shows the microstructure of the coating and substrate observed using an electron microscope using a back-scattered ion detector. The light-coloured phase represents the distribution of Re particles in the coating, the weight proportion of which is about $1 \%$. The structure of the coating shows deformed Ni-Cr powder particles in which the inclusions (bright particles in the SEM image) are scattered randomly in the form of Re particles with dimensions of a few micrometres.

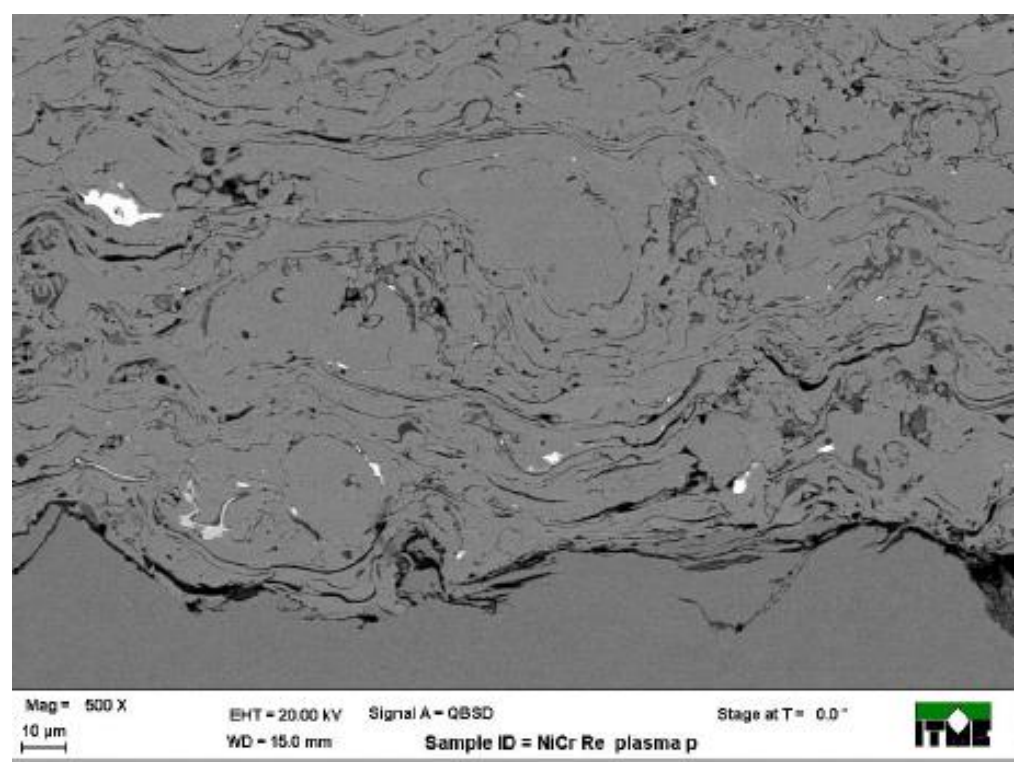

Figure 7 Microstructure of substrate and Ni-Cr-Re coating (SEM)

The plasma coating has a noticeable share of small and large pores. The small, closed pores are usually caused by trapped gases. Most of the larger pores are due to the formation of pits at the boundaries of the overlapping lamellae. In the plasma spraying method, the powder has been melted in a plasma with high thermal energy and deposited on a substrate in a semi-molten or molten form in an open atmosphere, resulting in a porous structure with a high content of oxides [6-8]. The cross-section of the coatings shows lamellar structures with the presence of thin oxide coatings, which is characteristic of plasma spraying. These oxides 
have been observed to follow the grain boundaries. A characteristic "two-zone" microstructure is observed on the surfaces of the sprayed coatings. It is made of well-melted lamellae, and between them there are sintering zones with grains on a submicrometric scale [1,7-9].

The next step was to measure the hardness of the coating using the Vickers method according to EN ISO 6507-1. The measurements were carried out under a load of 1,961N. Results are presented in the diagram (Figure 8).

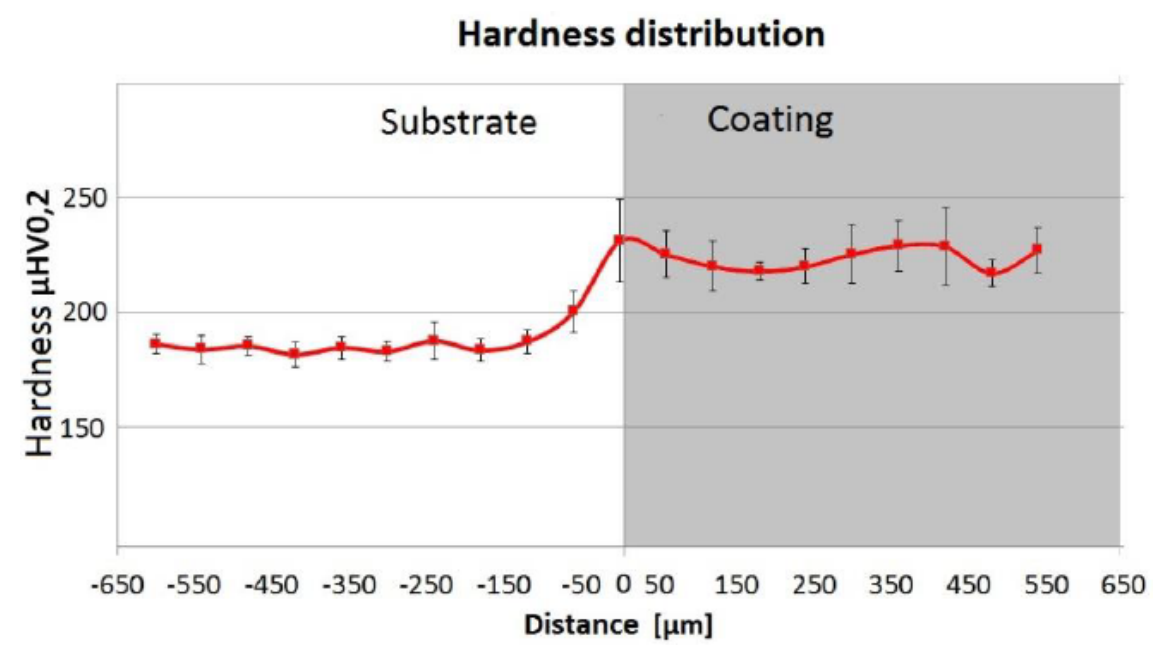

Figure 8 Hardness distribution in substrate-coating system

The graph shows the average hardness value from 5 measurement series with the standard deviation for the measurement point at the $95 \%$ confidence level. Measurement impressions were made at $60 \mu \mathrm{m}$ intervals. The hardness of the $16 \mathrm{Mo} 3$ steel substrate is approximately $180 \mathrm{HV} 0.2$ with a relatively low standard deviation, which indicates the homogeneity of the substrate material. The coating has a hardness in the range of 220$240 \mathrm{HV} 0.2$, with quite small range of standard deviation from the average values. This confirms the heterogeneity and irregular, diversified structure of the coating.

\section{CONCLUSION}

The plasma spraying process has a wide range of applications. With the appropriate selection of parameters, we can use various coating materials, metal, ceramic and composite. This method can be used for repair and regeneration purposes as well as for preventive purposes. Unfortunately, the sprayed coatings are porous. It is a good alternative to conventional surface modification methods, where precise coating thickness control is required. The coating material based on nickel and chromium is highly corrosion resistant. The addition of metallic rhenium to the powder increases the heat resistance of the alloy obtained in the process. A protective coating of this chemical composition increases resistance to high-temperature oxidation. Coatings with proper adhesion to the substrate were obtained. Typical for the thermal spraying processes, layers of oxides were observed at the boundary line between the coating and the substrate. The sprayed coating has a regular microstructure with a lamellar structure characteristic for this method of preparation. Characteristic thin oxide films for plasma sprayed coatings are visible between the powder particles from which the coating was formed. The obtained plasma sprayed $\mathrm{Ni}-\mathrm{Cr}-\mathrm{Re}$ coatings has a higher hardness than a substrate made of $16 \mathrm{Mo} 3$ steel, oscillating around the value of $230 \mathrm{HV} 0.2$. The particles of Re are evenly dispersed, they can be easily identified in the SEM image due to the high density of rhenium. In the microscopic image, we observe them in the form of bright inclusions with dimensions of a few micrometres. The interface between the coating and the substrate shows no defects and discontinuities. The coating material evenly fills the unevenness of the substrate surface. 


\section{ACKNOWLEDGEMENTS}

This research was funded by NCBR „Innovative Ni-Cr-Re coatings with enhanced corrosion and erosion resistance for high temperature applications in power generation industry" grant number NICRRE project4249 M-ERA.NET Call 2016, agreement number M-ERA.NET2/2016/01/2017

\section{REFERENCES}

[1] TOBOTA, K., CHMIELEWSKI, M., DUSZA, J. Microstructure and selected properties of Ni-Cr-Re coatings deposited by means of plasma thermal spraying. Welding Technology Review. [online]. 2020, vol. 92, no. 5, pp. 15-23. Available from: https://doi.org/10.26628/wtr.v92i5.1119.

[2] VARACALLE, D.J., GUILLEN, D.P., DEASON, D.M., RHODABERGER, W., SAMPSON, E. Effect of grit-blasting on substrate roughness and coating adhesion. Journal of Thermal Spray Technology, [online]. 2006, vol. 15, pp. 348-355. Available from: https://doi.org/10.1361/105996306X124347.

[3] KLIMPEL, A., CZUPRYNSKI, A., GÓRKA, J., KIK, T., MELCER, M. A study of modern materials for arc spraying Welding International. [online]. 2014, vol. 28, no. 2, pp. 100-106. Available from: https://doi.org/10.1080/09507116.2012.708479.

[4] KOŁODZIEJCZAK, P., GOLAŃSKI, D., CHMIELEWSKI, T., CHMIELEWSKI, M. Microstructure of Rhenium Doped Ni-Cr Deposits Produced by Laser Cladding. Materials. [online]. 2021, vol. 14, no. 11, p. 2745. Available from: https://doi.org/10.3390/ma14112745.

[5] GIAMEI, A.F., ANTON, D.I. Rhenium additions to a Ni-base superalloy: Effects on microstructure. Metallurgical Transactions A. [online]. 1985, vol. 16, pp. 1997-2005. Available from: https://doi.org/10.1007/BF02662400.

[6] SOKOLOWSKI, P., LATKA, L., PAWLOWSKI, L., AMBROZIAK, A., KOZERSKI, S., NAIT-ALI, B. Characterization of microstructure and thermal properties of YCSZ coatings obtained by suspension plasma spraying, Surface and Coatings Technology. [online]. 2015, vol. 268, pp. 147-152. Available from: https://doi.org/10.1016/i.surfcoat.2014.10.006.

[7] LI C, J., OHMORI, A. Relationships between the microstructure and properties of thermally sprayed deposits. Journal of Thermal Spray Technology. [online]. 2003, vol. 11, no. 3, pp. 365-374. Available from: https://doi.org/10.1361/105996302770348754.

[8] PAWŁOWSKI, A., CZEPPE, T., MAJOR, Ł., SENDEROWSKI, C. Structure morphology of Fe-Al coatings detonation sprayed onto carbon steel substrate. Archives of Metallurgy and Materials. 2009, vol. 54, no. 3, pp. 783-788.

[9] LATKA, L., SZALA, M., MICHALAK, M., PAŁKA, T. Impact of atmospheric plasma spray parameters on cavitation erosion resistance of Al2O3-13\% TiO2 coatings. Acta Physica Polonica A. [online]. 2019, vol. 13, no. 2, pp. 342347. Available from: https://doi.org/10.12693/APhysPolA.136.342. 